\title{
Protective effects of galangin against UVB irradiation-induced photo-aging in CCD-986sk human skin fibroblasts
}

\author{
Ye-Jin Kim ${ }^{1}$, Eun-Ho Lee ${ }^{1}$, Eun-Bi Cho ${ }^{1}$, Dong-Hee Kim² ${ }^{2}$ Byung-Oh Kim ${ }^{1}$ In-kyu Kang ${ }^{3}$, Hee-Young Jung ${ }^{4}$ \\ and Young-Je Cho ${ }^{1 *}$ (D)
}

\begin{abstract}
Photo-aging is caused by cumulative oxidative stress from ultraviolet B irradiation with up-regulating intracellular reactive oxygen species, 4-hydroxynonenal, and matrix metalloproteinases. MMPs are the enzyme that degrades collagens so that impair the function of the dermis. Galangin was identified by ${ }^{1} \mathrm{H}-\mathrm{NMR}$ and ${ }^{13} \mathrm{C}-\mathrm{NMR}$ spectroscopy and is a natural flavonol that recently known to have many pharmacological effects such as anti-viral, anti-inflammatory, anti-atopic dermatitis and anti-oxidative activities. In this study, the protective effect of galangin on UVB-induced photo-aging in human skin fibroblasts (CCD-986sk) was conducted by Western blot analysis and enzyme-linked immunosorbent assay. Activator protein 1 and nuclear factor-kappa B are the main transcription factors from activated mitogen-activated protein kinases that up-regulates MMPs. Galangin showed down-regulation of intracellular ROS, 4-HNE, and MMPs through inhibition of phosphorylation of the MAPK pathway and showed a protective effect against skin fibroblasts under oxidative stress caused by UVB irradiation. This lead to up-regulation of fibroblast growth factor 2 and type 1 pro-collagen. These findings suggest that galangin can be developed as a potential agent for functional food and cosmetics of UVB-induced skin photo-aging.
\end{abstract}

Keywords: Anti-wrinkle, CCD-986sk, Galangin, Photo-aging

\section{Introduction}

Skin aging can be caused by two types of aging factors: intrinsic aging factors and extrinsic aging factors. Intrinsic aging is a natural process of skin aging that depends on the passage of time perse. Over time, the physical function gets impaired and the production of reactive oxygen species (ROS) is increased, leading to skin aging [1]. Extrinsic aging is caused by several environmental factors such as smoking [2], pollution factors and ultraviolet (UV) irradiation. Consistently exposed UV is a major extrinsic aging factor that causes photo-aging and exhibits symptoms such as deep wrinkles, lack of moisture, reduced elasticity and skin disorders $[3,4]$. As more

\footnotetext{
*Correspondence: yjcho@knu.ac.kr

1 School of Food Science \& Biotechnology/Food \& Bio-Industry Research Institute, Kyungpook National University, 80 University Street, Bukgu, Daegu 41566, Republic of Korea

Full list of author information is available at the end of the article
}

frequent exposure of strong intensity of UV cause aged appearance and damage to the connective tissues such as elastin and collagen that are produced by fibroblasts in the dermis $[5,6]$.

Ultraviolet-B (UVB) irradiation is known to be responsible for the biological damage on the skin more than UVA, and cause skin photo-aging by up-regulation of two transcription factors, activator protein-1 (AP-1) and nuclear factor-kappa B (NF-kB), by producing ROS in human skin fibroblasts [4, 7]. UVB-induced ROS activate mitogen-activated protein kinases (MAPKs), such as extracellular signal-regulated kinase (ERK), p38 kinase and c-Jun $\mathrm{N}$-terminal kinase (JNK). These enzymes induce the generation of transcription factor AP-1, a heterodimer consisting of c-Jun and c-Fos. Phosphorylation of MAPKs results in activation of AP-1, causing gene expression of MMP-1, MMP-3, MMP-9 and inhibition of type 1 procollagen expression $[8,9]$. 
NF-kB, a heterodimer composed of p65 and p50, usually in the binding state with inhibitor-kappa B ( IkB) and is presented in the cytoplasm of human skin fibroblasts. UVB irradiation activates IkB kinase (IKK) to phosphorylate IkB and separate IkB and NF-kB $[10,11]$. The freed-up transcription factor NF-kB thereby migrates from the cytoplasm to the nucleus [12] and expresses the MMP-1, MMP-3 genes. Therefore, transcription factor AP-1 and NF-kB up-regulates collagen breakdown by MMPs such as MMP-1, MMP-3, and MMP-9 [13].

Galangin is a natural flavonol that has pharmacological effects such as anti-viral [14], anti-inflammatory [15], anti-atopic dermatitis [16], anti-oxidative activity [17] and used as materials for skin care cosmetics [18]. However, it is not known whether galangin is effective to prevent photo-aging in human skin fibroblasts. The structure of galangin was identified by ${ }^{1} \mathrm{H}-\mathrm{NMR}$ and ${ }^{13} \mathrm{C}$ NMR spectroscopy and this study were carried out to examine the effect of galangin on preventing photo-aging through MAPK signaling pathways in UVB irradiated human skin fibroblasts. Therefore, CCD-986sk human skin fibroblasts were used.

\section{Materials and methods Chemicals}

CCD-986sk human skin fibroblasts were purchased from American Type Culture Collection (ATCC; Manassas, VA, USA). Dulbecco's modified Eagle's medium (DMEM) was obtained from HyClone Laboratories, Inc. (Logan, UT, USA), while fetal bovine serum (FBS), penicillinstreptomycin were obtained from Gibco (Grand Island, NY, USA). 3-(4,5-dimethylthiazol-2yl)-2,5-diphenyltetrazolium bromide (MTT) obtained from Sigma Chemical Co. (St. Louis, MO, USA) and enzyme-linked immunosorbent assay (ELISA) was performed using ROS-Glo ${ }^{\mathrm{TM}}$ $\mathrm{H}_{2} \mathrm{O}_{2}$ assays (Promega, Madison, WI, USA) and pro-Collagen type $1 \mathrm{C}$-peptide protein Elisa kit (Takara, Shiga, Japan) and human FGF basic Quantikine ELISA kit (R\&D Systems., Minneapolis, MN, USA). All the antibodies used were obtained from Santa Cruz Biotechnology (Santa Cruz, CA, USA)

\section{Identification of the purified bioactive compound}

The ${ }^{1} \mathrm{H}-\mathrm{NMR}$ (CDCl3, $600 \mathrm{MHZ}$ ) spectrum showed a profile of $6.234(1 \mathrm{H}, \mathrm{d}, \mathrm{J}=2.1 \mathrm{~Hz}, \mathrm{H}-6), 6.485(1 \mathrm{H}, \mathrm{d}$, $\mathrm{J}=2.1 \mathrm{~Hz}, \mathrm{H}-8), 7.505-7.561\left(3 \mathrm{H}, \mathrm{m}, \mathrm{H}-3^{\prime}, \mathrm{H}-4^{\prime}, 5^{\prime}\right), 8.156$ $\left(2 \mathrm{H}, \mathrm{dd}, \mathrm{J}=1.5\right.$ and $\left.8.0 \mathrm{~Hz}, \mathrm{H}-2^{\prime}, 6^{\prime}\right)$, and the ${ }^{13} \mathrm{C}-\mathrm{NMR}$ $(\mathrm{CDCl} 3,62.9 \mathrm{MHz})$ spectrum showed a profile of 176.18 (C-4), 164.14 (C-7), 160.49 (C-5), 156.40 (C-9), 145.64 (C-2), 137.02 (C-3), 130.92 (C-1), 129.89 (C-4), 128.48 (C-2', C-6'), 127.51 (C-3', C-5'), 103.16 (C-10), 98.22 (C-6), 93.53 (C-8). The purified compound, a yellowgreen powder, was spread out in TLC which the color was developed into yellow color when heated with $10 \%$ $\mathrm{H}_{2} \mathrm{SO}_{4}$ sprayed. In the ${ }^{1} \mathrm{H}$-NMR spectrum, two protons were identified to be coupling in doublet at $8.156 \mathrm{ppm}$ $\left(2 \mathrm{H}, \mathrm{dd}, J=1.7,9.7 \mathrm{~Hz}, \mathrm{H}-2^{\prime}, 6^{\prime}\right) .6 .485 \mathrm{ppm}(1 \mathrm{H}, \mathrm{d}, J=2.1$ $\mathrm{Hz}, \mathrm{H}-8)$ and $6.234 \mathrm{ppm}(1 \mathrm{H}, \mathrm{d}, J=2.1 \mathrm{~Hz}, \mathrm{H}-6)$ was found to be coupling in $J=2.1 \mathrm{~Hz} .13$ Carbon signals were detected in the ${ }^{13} \mathrm{C}$-NMR spectrum but an overlapping peak of $128.48 \mathrm{ppm}\left(\mathrm{C}-2^{\prime}-, 6^{\prime}\right)$ and $127.51 \mathrm{ppm}\left(\mathrm{C}-3^{\prime}, 5^{\prime}\right)$ was detected which totals 15 carbons. With these results, purified compound from Alpinia officinarum Hance was identified as galangin.

\section{Cell culture}

Cells were plated in $75 \mathrm{~cm}^{2}$ culture flasks and grown in DMEM supplemented with $10 \%$ FBS and $5 \%$ penicillinstreptomycin in a $5 \% \mathrm{CO}_{2}$ incubator at $37{ }^{\circ} \mathrm{C}$. For the treatment, cells were cultured in fresh medium for $24 \mathrm{~h}$. After overnight incubation, the cells were washed with phosphate buffered saline (PBS; Gibco, Grand Island, NY, USA) and pretreated by UVB irradiation. After UVB irradiation, PBS was removed, and the cells were incubated in serum-free medium with galangin-treated for further $48 \mathrm{~h}$ more.

\section{Elastase and collagenase inhibition assay}

The elastase inhibitory activity was evaluated by the method of [19] with minor modifications. Simply, 1.0 U/ $\mathrm{mL}$ porcine pancreatic elastase and the sample or distilled water were added to the mixed solution of $0.2 \mathrm{M}$ Tris- $\mathrm{HCl}$ buffer ( $\mathrm{pH} 8.0$ ) and $0.8 \mathrm{mM} \mathrm{N}$-succinyl-(Ala) ${ }_{3}-\rho$-nitroanilide, then the absorbance was measured at $410 \mathrm{~nm}$.

The collagenase inhibition activity was proceeded by the method of [20] with minor modifications. Briefly, 0.2 $\mathrm{mg} / \mathrm{mL}$ collagenase and sample or distilled water were added to the mixed solution of $0.1 \mathrm{M}$ Tris- $\mathrm{HCl}$ buffer $(\mathrm{pH}$ 7.5) and 4-phenylazobenzyloxycarbonyl-Pro-LeuGly-Pro-D-Arg $(0.3 \mathrm{mg} / \mathrm{mL})$, then the absorbance was measured at $320 \mathrm{~nm}$. The inhibition rate of both elastase and collagenase was calculated as the following formula: Inhibition $(\%)=1-$ (absorbance of sample/absorbance of control) $\times 100$.

\section{Cell viability}

The toxicity of the galangin in skin fibroblasts was measured by using a MTT colorimetric assay. Briefly, $5 \times 10^{3}$ cells were seeded in 48-well plate and incubated for 24 h. Skin fibroblasts were subsequently exposed to UVB $\left(20 \mathrm{~mJ} / \mathrm{cm}^{2}\right)$ then incubated in the presence of galangin at a concentration of $5,10,20,25,50 \mu \mathrm{g} / \mathrm{mL}$ for $48 \mathrm{~h}$ in serum-free medium. After incubation, cell medium was replaced with MTT reagent and incubated for additional $4 \mathrm{~h}$. Then, all the medium was removed and dimethyl sulfoxide (DMSO) was added to dissolve insoluble formazan 
crystals. Cell viability was then measured at an absorbance of $540 \mathrm{~nm}$ with a micro-plate reader.

\section{Measurement of ROS}

Skin fibroblasts were seeded in 96-well plates and after $24 \mathrm{~h}$ incubation, the culture medium was replaced and pretreated with UVB $\left(20 \mathrm{~mJ} / \mathrm{cm}^{2}\right)$ for $1 \mathrm{~min}$. After UVB irradiation, they were treated with $5,10,25 \mu \mathrm{g} / \mathrm{mL}$ of galangin and incubated for $48 \mathrm{~h}$ in serum-free medium. The production of ROS was quantified using hydrogen peroxide assay kit (ROS-Glo ${ }^{\mathrm{TM}} \mathrm{H}_{2} \mathrm{O}_{2}$, Promega).

\section{Enzyme-linked immunosorbent assay (ELISA)}

Skin fibroblasts were seeded in plates and cultured for $24 \mathrm{~h}$. They were pretreated with UVB and $5,10,25 \mu \mathrm{g} /$ $\mathrm{mL}$ of galangin then incubated for $48 \mathrm{~h}$ in serum-free medium. The production of type 1 procollagen was quantified according to manufacturer's introductions (Takara, Shiga, Japan) so do fibroblast growth factor 2 (FGF2) (R\&D Systems Inc., Minneapolis, MN, USA). Then detected by using ELISA plate reader.

\section{Western blot analysis}

Skin fibroblasts were seeded in 6-well plates and grown for $24 \mathrm{~h}$, followed by galangin treatment for $48 \mathrm{~h}$. Skin fibroblasts were then lysed in radio immune precipitation assay (RIPA) lysis buffer (Pierce, Rockford, IL, USA) with protease inhibitor cocktails (100X). To obtain a supernatant, the lysate was centrifuged at $12,000 \mathrm{rpm}$ for $20 \mathrm{~min}$ at $4{ }^{\circ} \mathrm{C}$ and protein concentration was determined with a bicinochoninic acid (BCA) protein assay kit (Thermo scientific, USA). $20 \mu \mathrm{g}$ of each protein was separated by $10 \%$ sodium dodecyl sulfate-polyacrylamide gel electrophoresis (SDS-PAGE) and transferred to polyvinylidene difluoride (PVDF) membranes. The membranes were immediately placed in blocking buffer (5\% skim milk with
TBST) and blocked for $1 \mathrm{~h}$. Subsequently, PVDF membranes were incubated at $4{ }^{\circ} \mathrm{C}$ with primary antibodies against IkB, phosphor-IkB, nucleus NF-kB, cytoplasm NF-kB, c-Fos, c-Jun, MMP-1, MMP-3, MMP-9, p-38, phosphor-p-38, ERK, phospho-ERK, 4-HNE, $\beta$-actin (1:1000 dilution) for $24 \mathrm{~h}$. To detect primary antibodies, horseradish peroxidase (HRP)-conjugated secondary antibodies (1:1000 dilution) were incubated for $2 \mathrm{~h}$. Signals were detected using the Super Signal West Pico chemiluminescent substrate (Pierce, Rockford, IL, USA) under a LAS 4000 image analyzer (Fuji Film Life Science, Tokyo, Japan).

\section{Statistical analysis}

All the results in this study were obtained from the average of triplicate experiment data, and the mean values and standard deviations were analyzed using one-way ANOVA in SPSS 23 program (Statistical Package for Social Science, Chicago, IL, USA). Analysis of variance Duncan's multiple range test and one-way ANOVA were used to compare the significance of differences between the samples at $\mathrm{P}<0.05$ level. Differences among the means were determined by a $t$-test, and values of $P<0.05$ and $P<0.01$ were considered statistically significant.

\section{Results and discussion}

\section{Elastase and collagenase inhibitory activities of galangin}

The elastase inhibitory effect of galangin was conducted in the concentration range of $50-200 \mu \mathrm{g} / \mathrm{mL}$ and was compared with ursolic acid. At 50-100 $\mu \mathrm{g} / \mathrm{mL}$, inhibition rates between the two concentrations were similar, all lower than that of ursolic acid. However, at 150-200 $\mu \mathrm{g} /$ $\mathrm{mL}$, the inhibition rates of both concentrations exceeded the inhibition rate of ursolic acid, reaching 78-85\% (Fig. 1a). For the collagenase inhibitory effect, epigallocatechin gallate (EGCG) was used as a positive control.
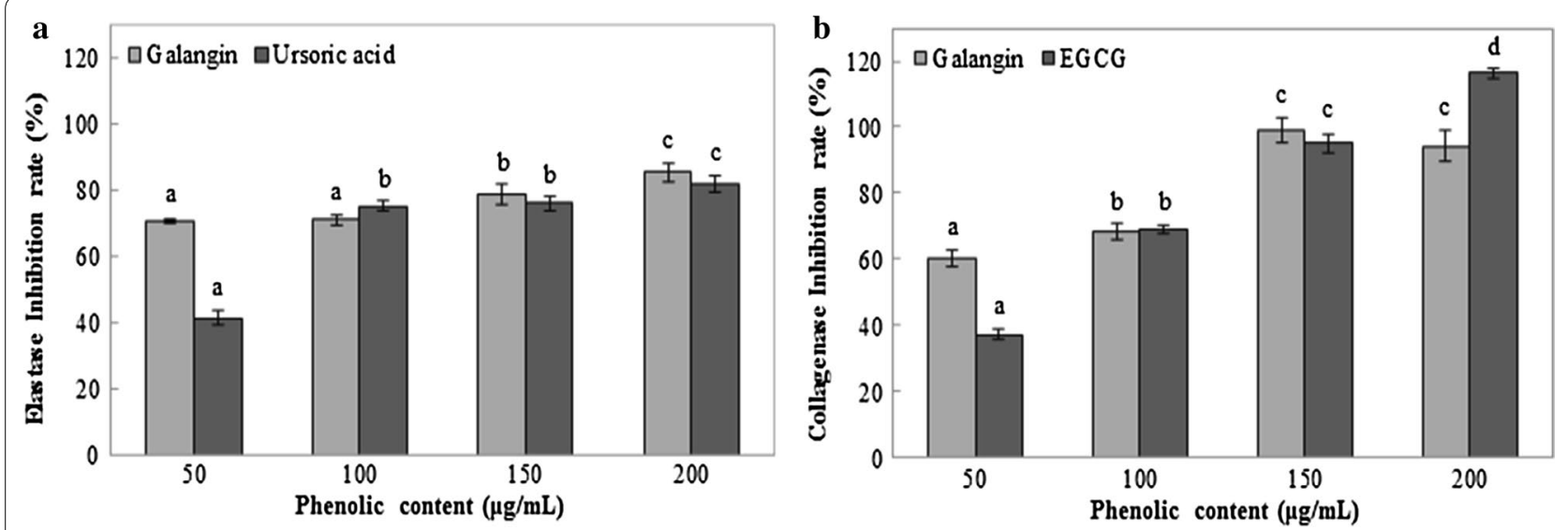

Fig. 1 Inhibitory activity of galangin on elastase (a) and collagenase (b). The results were expressed as means of triplicates \pm standard derivation with different superscript letters are significantly different at $P<0.05$ by Duncan's multiple range test $(\mathrm{n}=3)$ 


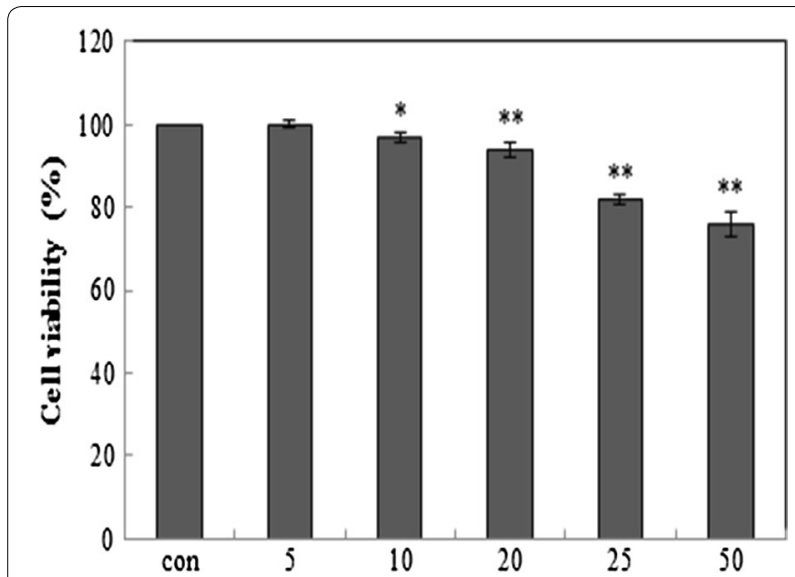

Fig. 2 Cell viability of CCD-986sk human skin fibroblasts with galangin for $72 \mathrm{~h}$. The results were expressed as means of triplicates \pm standard derivation. ${ }^{*} P<0.05$ and ${ }^{*} P<0.01$ compared with control

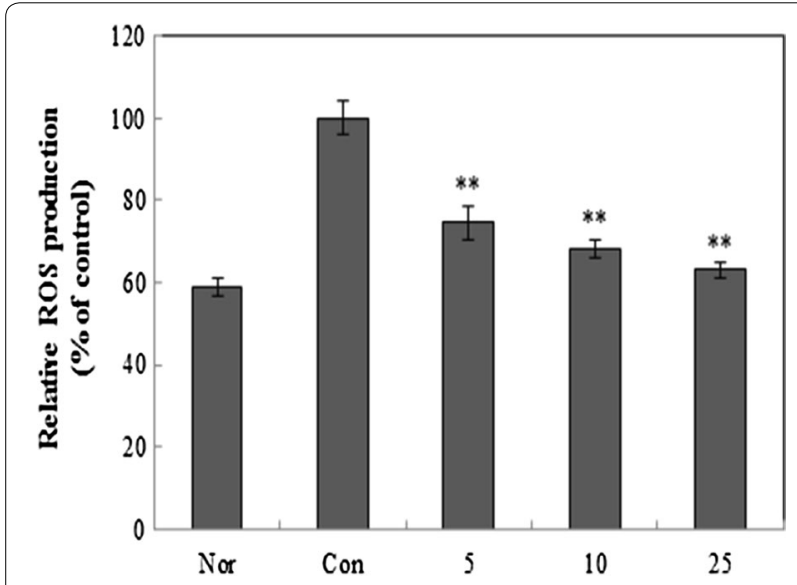

Fig. 3 ROS of CCD-986sk human skin fibroblasts after pre-treatment by UVB $\left(20 \mathrm{~mJ} / \mathrm{cm}^{2}\right)$, then treatment with a various concentration of a galangin for $72 \mathrm{~h}$. The results were expressed as means of triplicates \pm standard derivation. ${ }^{*} P<0.05$ and ${ }^{*} P<0.01$ compared with control
At $150-200 \mu \mathrm{g} / \mathrm{mL}$, galangin inhibition rates was higher than $90 \%$ (Fig. 1b).

\section{Cell viability}

MTT assay was performed to determine the viability of $5,10,20,25$, and $50 \mu \mathrm{g} / \mathrm{mL}$ galangin-treated cells, and the concentration range of galangin to be used in the remaining experiments was set. The results showed that galangin concentration did not affect cell viability when the concentration was lower than $25 \mu \mathrm{g} / \mathrm{mL}$, so the concentration of 5,10 and $25 \mu \mathrm{g} / \mathrm{mL}$ galangin was used for subsequent experiments (Fig. 2).

\section{Measurement of ROS}

This experiment was conducted to evaluate the effect of reducing the generation of UVB-induced intracellular ROS by galangin. Galangin-treated cells inhibited UVBinduced intracellular ROS levels up to 74.5, 68.2, 63.2\% at $5,10,25 \mu \mathrm{g} / \mathrm{mL}$ respectively, compared to that of the UVB irradiated control (Fig. 3).

\section{Measurement of FGF-2 and type 1 procollagen}

The effect of galangin on a synthesis of FGF-2 and type 1 procollagen was assessed by ELISA. UVB irradiation on skin fibroblasts reduced FGF- 2 and type 1 procollagen by $60.9 \%$ and $70.9 \%$, respectively. However, after treatment with galangin at a concentration of 5,10 and $25 \mu \mathrm{g} / \mathrm{mL}$, the expression of FGF-2 gradually increased to 60.8, 63.6 and $69.8 \%$, respectively, and type 1 procollagen increased to $75.7,77$ and $79.1 \%$. These results suggest that skin fibroblasts irradiated with UVB can be restored by treating galangin, although the expression of FGF-2 and type 1 procollagen is reduced (Fig. 4).
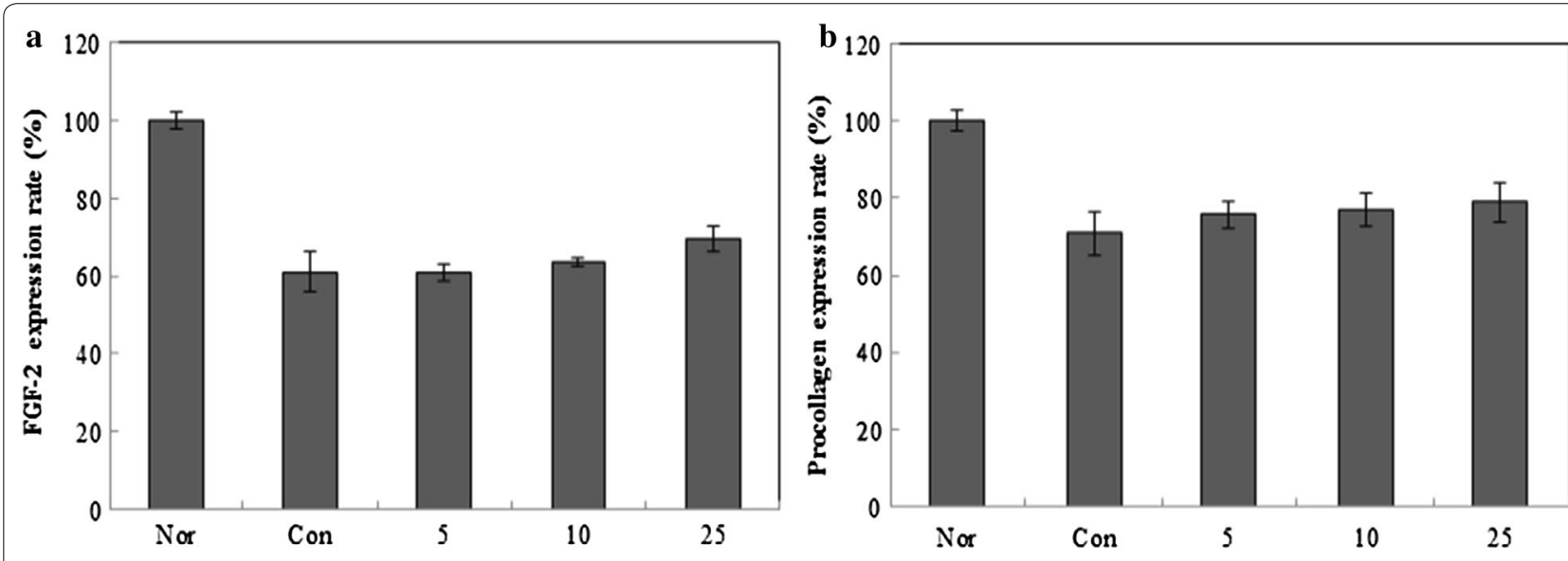

Fig. 4 Effect of galangin on FGF-2 (a) and type 1 procollagen (b) expression. CCD-986sk human skin fibroblasts were pre-treated by UVB (20 mJ/ $\mathrm{cm}^{2}$ ), then treated with various concentration of galangin for $72 \mathrm{~h}$. The results were expressed as means of triplicates \pm standard derivation. ${ }^{*} P<$ 0.05 and ${ }^{*} P<0.01$ compared with control 

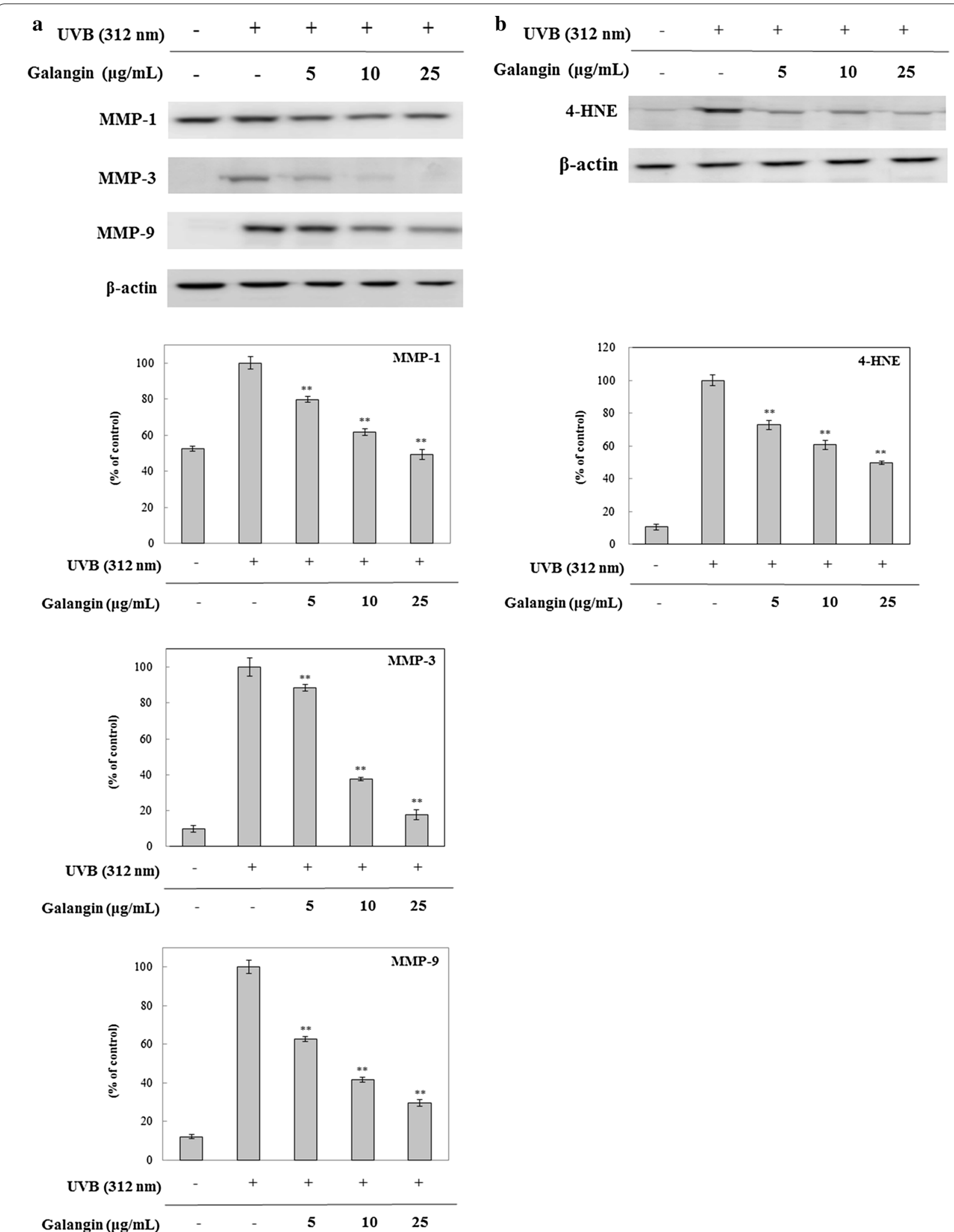

Fig. 5 Effect of galangin on modulation of MMPs (a) and 4-HNE (b) expression. CCD-986sk human skin fibroblasts were pre-treated by UVB (20 mJ/ $\mathrm{cm}^{2}$ ), then treated with various concentration of galangin for $72 \mathrm{~h}$. The results were expressed as means of triplicates \pm standard derivation. ${ }^{*} P<$ 0.05 and ${ }^{* *} P<0.01$ compared with control 


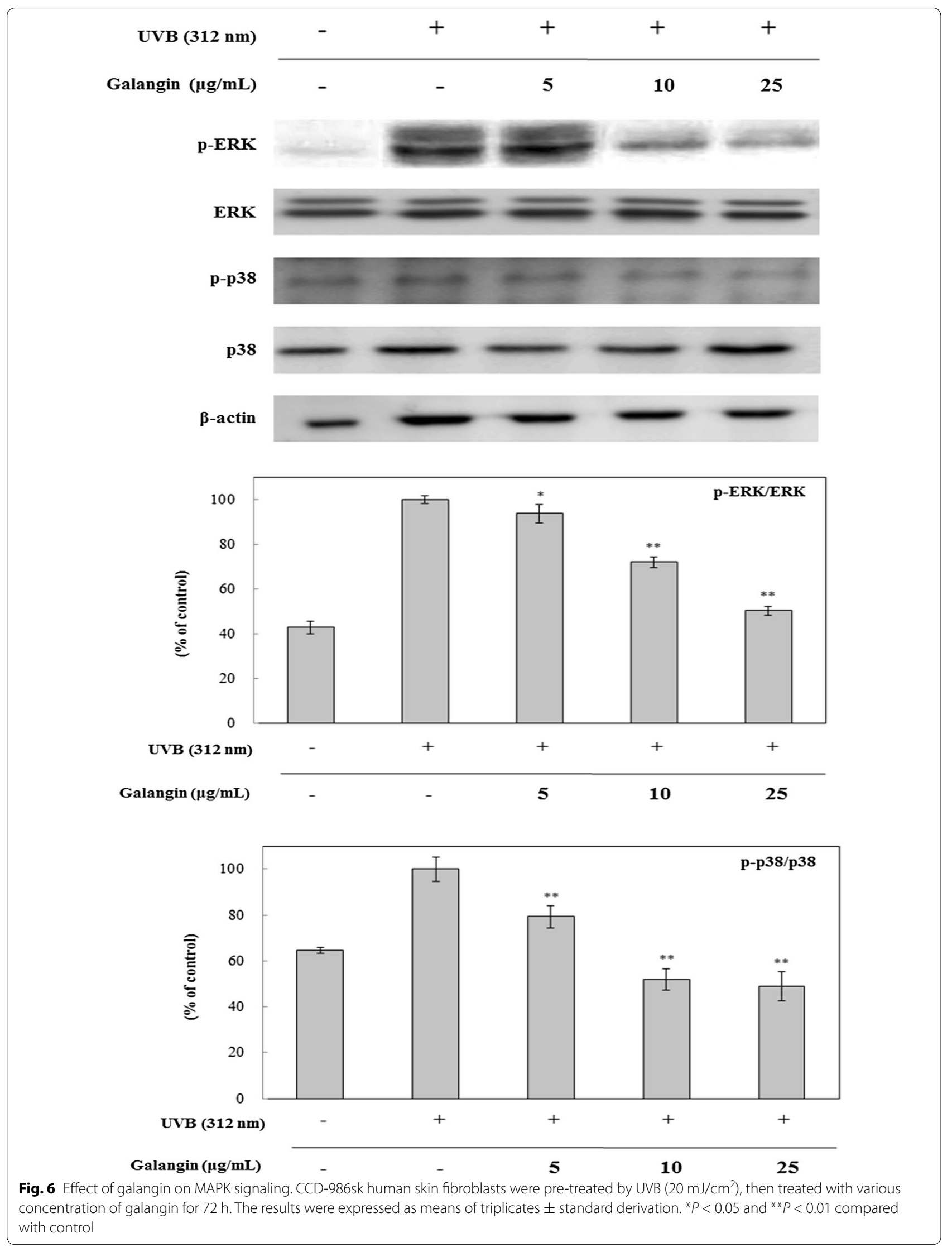



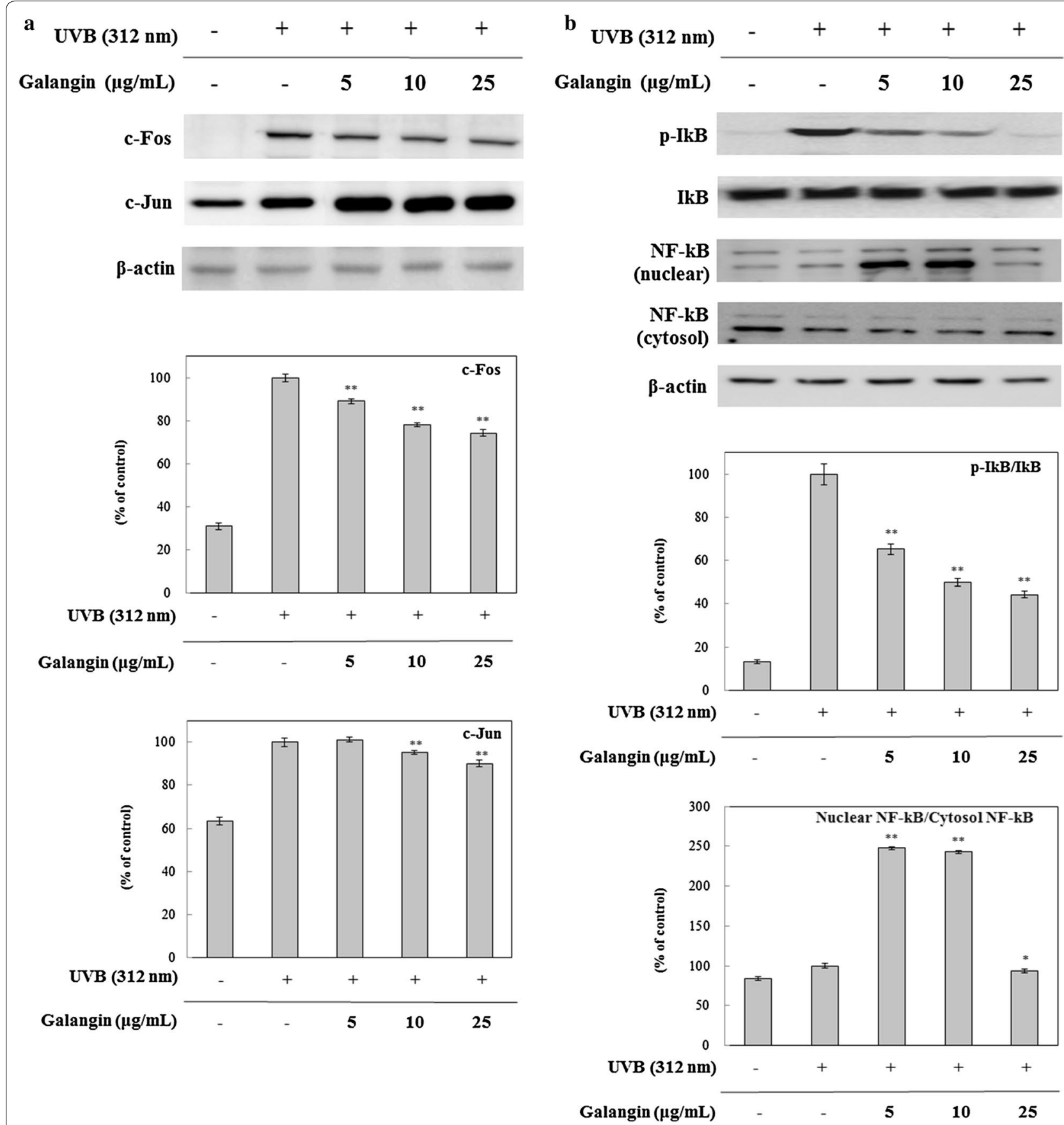

Fig. 7 Effect of galangin on changes in AP-1 (a) and NF-kB (b) expression levels. CCD-986sk human skin fibroblasts were pre-treated by UVB (20 mJ/ $\mathrm{cm}^{2}$ ), then treated with various concentration of galangin for $72 \mathrm{~h}$. The results were expressed as means of triplicates \pm standard derivation. ${ }^{*} P<$ 0.05 and ${ }^{*} P<0.01$ compared with control

\section{Effect of galangin on MMPs and 4-HNE expression} UVB irradiation causes ROS in the skin fibroblasts, which produces lipid peroxidation products such as 4-HNE and activates transcription factors such as AP-1 and NF-kB [21]. Activated AP-1 and nuclear NF-kB upregulate the expression of MMP-1, MMP-3, and MMP-9 that degrades collagen of intracellular fibroblasts or inhibit the production of type 1 procollagen [8]. As shown in Fig. 5, UVB induced the expression of MMPs and after treatment with 5, 10, $25 \mu \mathrm{g} /$ $\mathrm{mL}$ galangin, the expression of MMPs and 4-HNE was decreased in a dose-dependent manner. 


\section{Effect of galangin on MAPK signaling pathway}

Activation of the MAPK signaling pathway by sustained exposure of UVB can damage the skin dermis and produce collagen-degrading enzyme, MMPs [22]. To investigate the inhibition effect of galangin on phosphorylation of MAPK proteins due to UVB irradiation, the expression level of phosphorylated ERK and p38 were measured by western blot. The results show that phosphorylation of MAPKs (ERK, p38) activated by UVB irradiation is inhibited by treatment with galangin in a dose-dependent manner (Fig. 6). When the MAPK signaling pathway is activated by UVB stimulation, the MAPK protein phosphorylates the heterodimers c-Jun and c-Fos of transcription factor AP-1 and NF-kB to upregulate MMPs [23]. First, expression levels of c-Jun and c-Fos were measured by Western blotting and showed galangin reducing the activation of c-Jun and c-Fos (Fig. 7a). Next, gene expression of related genes IkB and NF-kB were also examined by Western blotting (Fig. 7b). The results showed that galangin inhibited the phosphorylation of IkB in a dose-dependent manner, inhibiting NF-kB from migrating to the nucleus at a concentration of $25 \mu \mathrm{g} / \mathrm{mL}$.

\section{Acknowledgements}

Not applicable.

\begin{abstract}
Authors' contributions
YJK and EHL analyzed the data and wrote the paper. DHK, BOK and IKK provided technical assistance to YJK and helped with the data collection. EBC edited the manuscript. HYJ and YJC supervised the work. EHL revised and edited the manuscript and supervised the work. All authors read and approved the final manuscript.
\end{abstract}

\section{Funding}

Not applicable.

\section{Availability of data and materials \\ Not applicable.}

\section{Competing interests}

The authors declare that they have no competing interests.

\section{Author details}

${ }^{1}$ School of Food Science \& Biotechnology/Food \& Bio-Industry Research Institute, Kyungpook National University, 80 University Street, Bukgu, Daegu 41566, Republic of Korea. ${ }^{2}$ Traditional Korean Medicine Technology Division, R\&D Department, Applied Product Development Team, National Development Institute of Korean Medicine, 94, Hwarang ro (Gapje-dong), Gyeongsan-si, Gyeongbuk 38540, Republic of Korea. ${ }^{3}$ Department of Horticultural Science, Kyungpook National University, 80 University Street, Bukgu, Daegu 41566 , Republic of Korea. ${ }^{4}$ School of Applied Biosciences, Kyungpook National University, 80 University Street, Bukgu, Daegu 41566, Republic of Korea.

Received: 7 May 2019 Accepted: 11 July 2019

Published online: 01 August 2019
2. Bernhard D, Moser C, Backovic A, Wick G (2007) Cigarette smoke-an aging accelerator. Exp Geron 42(3):160-165

3. Farage MA, Miller KW, Elsner P, Maibach HI (2008) Intrinsic and extrinsic factors in skin ageing: a review. Intern J Cosm Sci 30(2):87-95

4. Kammeyer A, Luiten RM (2015) Oxidation events and skin aging. Ageing Res Rev 21:16-29

5. Ortonne JP (2002) Photoprotective properties of skin melanin. British Journal of Dermatology 146:7-10

6. Naylor EC, Watson RE, Sherratt MJ (2011) Molecular aspects of skin ageing. Maturitas 69(3):249-256

7. Afaq F, Adhami VM, Mukhtar H (2005) Photochemoprevention of ultraviolet B signaling and photocarcinogenesis. Mutat Res 571(1-2):153-173

8. Fisher GJ, Wang Z, Datta SC, Varani J, Kang S, Voorhees JJ (1997) Pathophysiology of premature skin aging induced by ultraviolet light. New Eng J Med 337(20):1419-1429

9. Pittayapruek P, Meephansan J, Prapapan O, Komine M, Ohtsuki M (2016) Role of matrix metalloproteinases in photoaging and photocarcinogenesis. Int J Mol Sci 17(6):868-876

10. Lee YR, Noh EM, Jeong EY, Yun SK, Jeong YJ, Kim JH, Kwon KB, Kim BS, Lee SH, Park CS, Kim JS (2009) Cordycepin inhibits UVB-induced matrix metalloproteinase expression by suppressing the NF-KB pathway in human dermal fibroblasts. Exp Mol Med 41(8):548-554

11. He G, Karin M (2011) NF-kB and STAT3-key players in liver inflammation and cancer. Cell Res 21(1):159-165

12. Nakanishi C, Toi M (2005) Nuclear factor-kB inhibitors as sensitizers to anticancer drugs. Nature Reviews Cancer 5(4):297-305

13. Lee YR, Noh EM, Han JH, Kim JM, Hwang JK, Hwang BM, Chung EY, Kim BS, Lee SH, Lee SJ, Kim JS (2012) Brazilin inhibits UVB-induced MMP-1/3 expressions and secretions by suppressing the NF-KB pathway in human dermal fibroblasts. Eur J Pharmacol 674:80-86

14. Meyer JJM, Afolayan AJ, Taylor MB, Erasmus D (1997) Antiviral activity of galangin isolated from the aerial parts of Helichrysum aureonitens. J Ethnopharm 56(2):165-169

15. Lee HN, Shin SA, Choo GS, Kim HJ, Park YS, Kim BS, Kim SK, Cho SD, Nam JS, Choi CS, Che JH, Park BK, Jung JY (2018) Anti- inflammatory effect of quercetin and galangin in LPS-stimulated RAW264.7 macrophages and DNCB-induced atopic dermatitis animal models. Int J Med 41(2):888-898

16. Choi JK, Kim SH (2014) Inhibitory effect of galangin on atopic dermatitislike skin lesions. Food Chem Toxicol 68:135-141

17. Russo A, Longo R, Vanella A (2002) Antioxidant activity of propolis: role of caffeic acid phenethyl ester and galangin. Fitoterapia 73:S21-\$29

18. Ghisalberti C (2008) U.S. Patent No. 7371396. Washington, DC: U.S. Patent and Trademark Office

19. Kraunsoe JA, Claridge TD, Lowe G (1996) Inhibition of human leukocyte and porcine pancreatic elastase by homologues of bovine pancreatic trypsin inhibitor. Biochemistry 35:9090-9096

20. Wünsch E, Heidrich HG (1963) Zur quantitativen bestimmung der kollagenase. Hoppe-Seyler's Zeitschrift für physiologische Chemie 333:149-151

21. Larroque-Cardoso P, Camaré C, Nadal-Wollbold F, Grazide MH, Pucelle M, Garoby-Salom S, Zarkovic K (2015) Elastin modification by 4-hydroxynonenal in hairless mice exposed to UV-A. Role in photoaging and actinic elastosis. J Invest Derm 135(7):1873-1881

22. Kohl E, Steinbauer J, Landthaler M, Szeimies RM (2011) Skin ageing. J Euro Acad Derm Venereol 25(8):873-884

23. Benbow U, Brinckerhoff CE (1997) The AP-1 site and MMP gene regulation: what is all the fuss about. Matrix Biol 15:519-526

\section{Publisher's Note}

Springer Nature remains neutral with regard to jurisdictional claims in published maps and institutional affiliations.

\section{References}

1. Fisher GJ, Kang S, Varani J, Bata-Csorgo Z, Wan Y, Datta S, Voorhees JJ (2002) Mechanisms of photoaging and chronological skin aging. Arch Derm 138(11):1462-1470 